\title{
Study of diagnosis and management of ectopic pregnancy
}

\author{
Seema Patel*, Ajesh Desai
}

Department of Obstetrics and Gynecology, GMERS Medical Collage, Sola, Ahmedabad, Gujarat, India

Received: 11 April 2019

Accepted: 08 May 2019

\section{*Correspondence:}

Dr. Seema Patel,

E-mail: drkalpesh1974@yahoo.com

Copyright: (c) the author(s), publisher and licensee Medip Academy. This is an open-access article distributed under the terms of the Creative Commons Attribution Non-Commercial License, which permits unrestricted non-commercial use, distribution, and reproduction in any medium, provided the original work is properly cited.

\section{ABSTRACT}

Background: Diagnosis of ectopic pregnancy was frequently missed. Aim of the study was to determine the clinical presentation, and treatment associated with ectopic pregnancy.

Methods: This is a prospective study which was carried out at Obstetrics and Gynaecology department, GMERS SOLA civil hospital from August 2017 to October 2018. Total 416 patients were admitted during study period out of them 50 patients diagnosed with ectopic pregnancy were enrolled in the study and information was collected and analysed.

Results: $80 \%$ patients were between the age group of 21-30 years. 56\% patients were nulliparous. Amenorrhea (92\%) with lower abdominal pain (94\%) is the most common presenting symptom. $26 \%$ of patients show typical triad of amenorrhea, abdominal pain and bleeding per vagina. UPT and USG were most commonly performed investigations. 96\% cases showed UPT positive. 100\% USG showed adnexal pathology. Serum beta-hCG was done in 37 patients as an aid for diagnosis and to decide the line of management. Conservative medical management with Injection MTX was done in 4 patients of which 1 patients required laparotomy later on. Surgical management was done in $90 \%$ of patients. Laparoscopic management was done in $54 \%$ of cases.

Conclusions: Early diagnosis and timely intervention in the form of conservative or surgical treatment will help in reducing the morbidity and mortality associated with ectopic pregnancy.

Keywords: Amenorrhea, Ectopic pregnancy, Laparotomy, Ruptured ectopic pregnancy, Transvaginal scan, S. $\beta$-hCG

\section{INTRODUCTION}

The term "Ectopic Gestation" is applied to pregnancy where fertilized ovum becomes implanted at the site other than endometrial lining of the normal uterine cavity. ${ }^{1}$

Ectopic gestation is unmitigated disaster of human reproduction. Ectopic pregnancy is the leading cause of maternal morbidity in first trimester and is a major cause of reduced childbearing potential. The incidence of ectopic pregnancy is approximately $1.5-2 \%$ worldwide. $^{2}$ Rates for recurrent ectopic pregnancy varied between $4.2 \%$ and $5 \% .^{3}$

There is an overall increase in incidence of ectopic tubal pregnancy (ETP) and this is probably due to increased awareness, advanced diagnostic tools like transvaginal ultrasonography and estimation of beta subunit of human chorionic gonadotrophin $(\beta-\mathrm{hCG})$ in serum. ${ }^{4}$

Some associated risk factors are considered to be partially responsible for rise in incidence of ectopic pregnancy to its epidemic proportions in western world. Increased use of the intrauterine devices for contraception and use of assisted reproductive technologies (ART) are responsible factors for the ectopic pregnancy. ${ }^{3-7}$ Incidence after conceiving by use of ART is $2-2.5 \% .^{8}$

Till today ectopic pregnancy has always challenged ingenuity of the Obstetrician and Gynecologist by its bizarre clinical picture. If it is not attended in time, it may lead to maternal morbidity and mortality. It is one, which 
can mimic practically each and every gynecological disorder as well as many surgical catastrophes. ${ }^{9}$

Due to advance in modern technology like diagnostic laparoscopy, radioimmunoassay of $\mathrm{HCG}$ and ultrasonography diagnosis has become less difficult. Yet each method is having its own limitation. An accurate history and physical examination and its correlation to the modern diagnostic technology are believed to be the most important in the diagnosis. ${ }^{8-12}$

Modern anesthesia, blood transfusion facilities, transport facilities, immediate resuscitation as well as adequate and proper surgery are the keystone of success in reducing the maternal morbidity and further successful obstetric career.

High resolution ultra sonography and serum $\beta$-hCG level are useful for early detection of ectopic pregnancy in un ruptured state. ${ }^{11}$ Early diagnosis allows options for treatment by minimally invasive surgery or medical treatment under care of skilled personnel. ${ }^{9}$

In the last decade, management options have shifted towards conservative surgical and non-surgical treatment of un ruptured ectopic pregnancy. Consequently, there has been improvement in fertility rate after a previous ectopic pregnancy. ${ }^{13}$

Rapidly changing diagnostic and therapeutic approaches makes ectopic pregnancy an exciting and dynamic field for study.

The subject of Ectopic Pregnancy management is selected with following aims and objectives to study different modes of clinical presentation of patient, role of different diagnostic modalities, different modalities of management and its success rate in ectopic pregnancy.

\section{METHODS}

This is a prospective study which was carried out at Obstetrics and Gynaecology Department, GMERS Sola Civil Hospital from August 2017 to October 2018.

All the patients who were admitted with a history of amenorrhea, abdominal pain and irregular bleeding per vaginum during first trimester were subjected to various investigative procedures for the diagnosis of ectopic pregnancy. The diagnostic procedures include positive urine pregnancy test, clinical acumen, serum $\beta$-HCG levels, and transvaginal ultrasonography.

The treatment modalities include medical treatment with methotrexate in patients who are hemodynamically stable, unruptured ectopic pregnancy, adnexal mass <3.5 $\mathrm{cm}$ and $\beta$-HCG level less than $10,000 \mathrm{mIU} / \mathrm{ml}$. Surgical treatment includes laparoscopy or laparotomy depending on the clinical presentation and severity of the presentation
Total 416 patients were admitted during study period out of them 50 patients diagnosed with ectopic pregnancy were enrolled in the study and information was collected and analysed.

\section{Inclusion criteria}

The women who were diagnosed as ectopic pregnancy cases, who were in the reproductive age group of 15-44 years.

\section{Exclusion criteria}

There are no exclusion criteria.

All selected outcome variables were recorded and data were analysed. Statistically analysis was performed by using analytical tool pack of Microsoft excel - 2010 and 2007.

\section{RESULTS}

Total 416 patients were admitted with a history of amenorrhea, abdominal pain and irregular bleeding per vaginum in during trimester. In fourteen months, study period total 50 patients diagnosed with ectopic pregnancy incidence was $12.1 \%$.

In present study, $80 \%$ patients were between the age group of 21-30 years. The higher incidence in this age group was due to maximum fertility during 21-30 years of reproductive age (Figure 1).

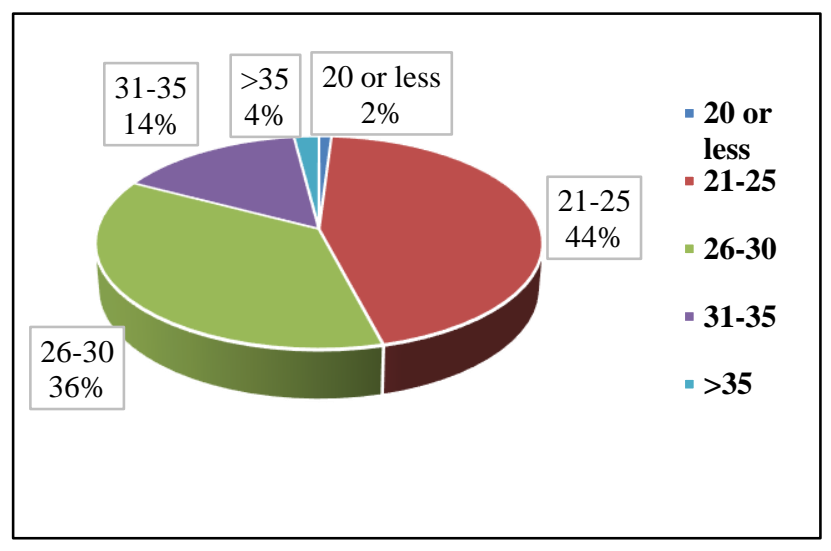

Figure 1: Age group (in years).

As per study, $56 \%$ patients were nulligravida and $26 \%$ were primipara. This suggests that incidence of ectopic pregnancy decrease with increase in parity (Figure 2).

Patients presented with more than one symptom. Lower abdominal pain is the most common presenting symptom in $94 \%$ of cases. $92 \%$ of patients had amenorrhea while in $56 \%$ of patients had history of bleeding or spotting per vaginum with abdominal pain 2-3 days before diagnosis which were considered as normal menses by patients but 
pregnancy tests were positive in those cases. $56 \%$ of patients presented with classical triad of abdominal pain, amenorrhea and bleeding per vaginum (Figure 3 ).

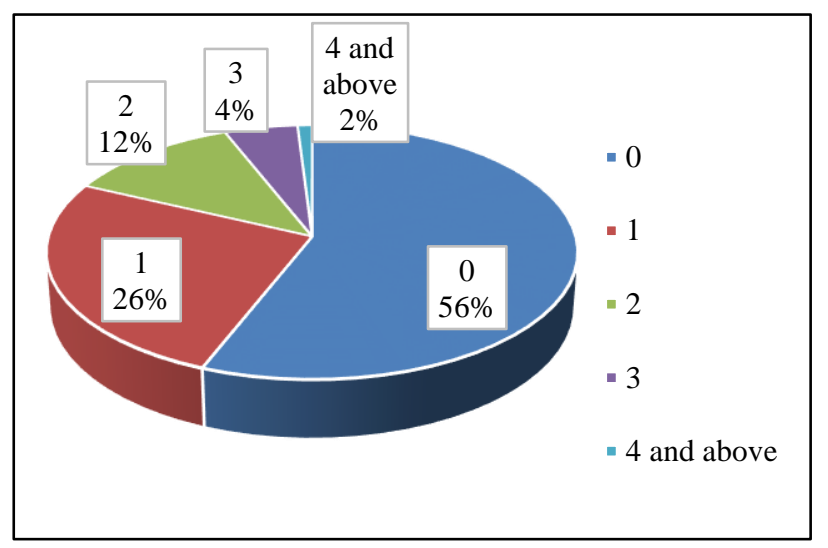

Figure 2: Parity.

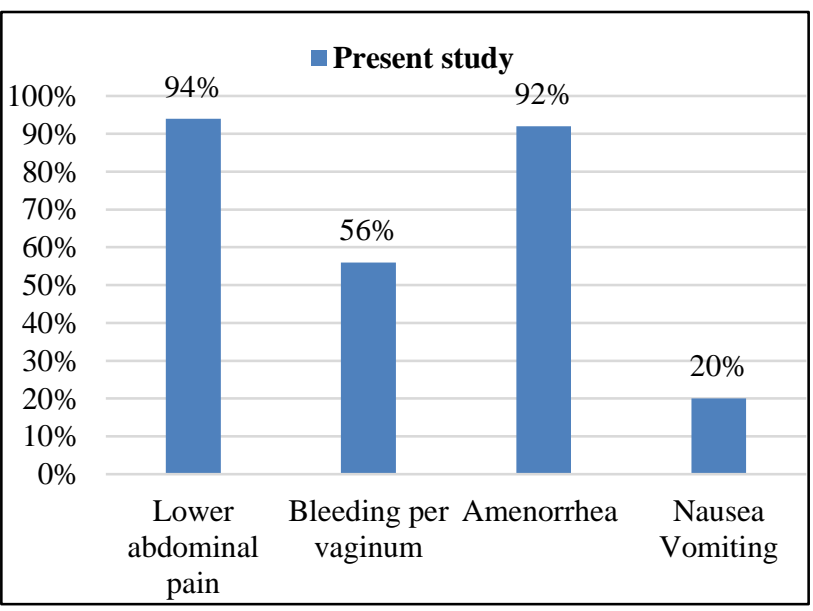

Figure 3: Symptoms.

More than one sign was present in each patient. History of syncope or collapse found in $12 \%$ of cases, which indicate massive blood loss with intraperitoneal collection. Abdominal and forniceal tenderness were present in $72 \%$ and $66 \%$ of cases respectively. This is due to peritoneal inflammation or irritation. The severity of the symptoms and signs depends on the stage of condition, but in unruptured ectopic gestation, symptoms are less predictive than in ruptured ectopic pregnancy (Table 1).

Table 1: Clinical signs.

\begin{tabular}{|lll|}
\hline Signs & No. of cases & Percentage \\
\hline Syncope/collapse & 6 & $12 \%$ \\
\hline Pallor & 22 & $44 \%$ \\
\hline Tachycardia & 13 & $26 \%$ \\
\hline Abdominal tenderness & 36 & $72 \%$ \\
\hline Forniceal tenderness & 33 & $66 \%$ \\
\hline Mass in fornix & 23 & $46 \%$ \\
\hline
\end{tabular}

Urine pregnancy was done 48 patients, it was positive in 46 patients. USG was conclusive in $100 \%$ of cases but sometimes it cannot differentiate between early ruptured or unruptured ectopic pregnancy accurately. RCOG guidelines 2016 suggest that transvaginal ultrasound has reported sensitivities of $87.0-99.0 \%$ and specificities of 94.0-99.9\% for the diagnosis of ectopic pregnancy (Table 2). ${ }^{14}$

Table 2: Investigations.

\begin{tabular}{|lll|l|}
\hline Investigations & $\begin{array}{l}\text { Done } \\
\text { (No. of } \\
\text { cases) }\end{array}$ & $\begin{array}{l}\text { Positive } \\
\text { (no of } \\
\text { cases) }\end{array}$ & $\begin{array}{l}\text { Accuracy } \\
(\%)\end{array}$ \\
\hline UPT & 48 & 46 & $95.83 \%$ \\
\hline USG & 100 & 100 & $100 \%$ \\
\hline S. beta hCG & 37 & 37 & $100 \%$ \\
\hline
\end{tabular}

The fallopian tube is by far most common site of ectopic implantation, accounting for $90 \%$ of all ectopic pregnancy in present study. It is comparable to Yakasai et al. ${ }^{15}$ One case of rudimentary horn (non-communicating) pregnancy was found during laparotomy which was managed by excision of horn with ectopic mass. ${ }^{16}$ Three patients presented with scar ectopic pregnancy. Two was managed surgically and the other by methotrexate. ${ }^{17,18}$ One cases of ovarian pregnancy were managed surgically (Figure 4).

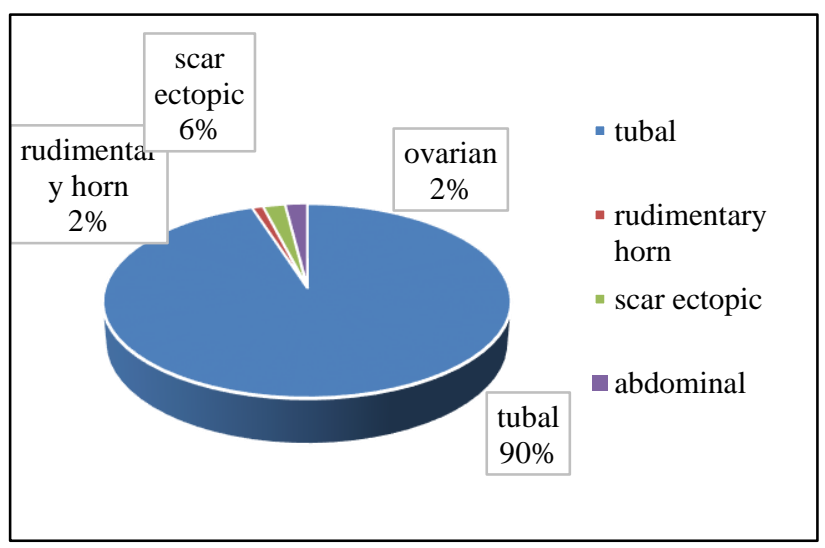

Figure 4: Site of ectopic pregnancy

There were $8 \%$ of clinically stable patients having unruptured ectopic pregnancy and mass of ectopic gestation $<3.5 \mathrm{~cm}$ were treated with medical management with multidose methotrexate therapy and serial beta-hCG monitoring. $2 \%$ patients was initially managed by MTX but later on laparotomy performed due to rupture of ectopic mass after single dose of inj. Methotrexate. Emergency laparotomy was done in $36 \%$ of patients who were referred to our institute from private hospitals or peripheral centres or came as emergency patients and presented with ruptured ectopic pregnancy and were haemodynamically unstable. Laparoscopic salpingectomy was done in $54 \%$ of patients (Figure 5). 


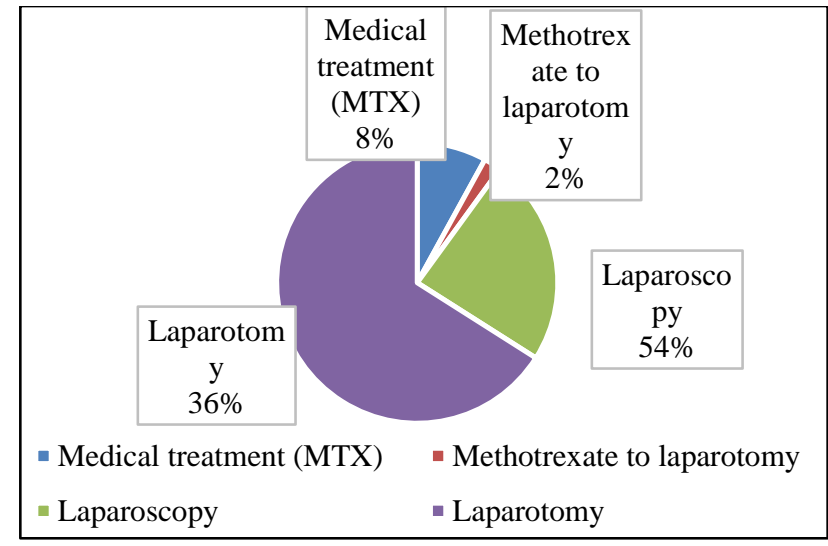

Figure 5: Mode of treatment.

Success rate of medical treatment was $80 \%$ as 1 patient out of 4 required laparotomy. Laparoscopy and laparotomy were performed on $54 \%$ and $36 \%$ cases successfully respectively. (Table 3 ).

Table 3: Success rate of treatment.

\begin{tabular}{|lll|}
\hline $\begin{array}{l}\text { Mode of } \\
\text { treatment }\end{array}$ & $\begin{array}{l}\text { Success rate } \\
(\%)\end{array}$ & $\begin{array}{l}\text { Hoover et al } \\
(\%)\end{array}$ \\
\hline Methotrexate & $80 \%$ & $94.7 \%$ \\
\hline Laparoscopy & $100 \%$ & $91.4 \%$ \\
\hline Laparotomy & $100 \%$ & $100 \%$ \\
\hline
\end{tabular}

\section{DISCUSSION}

Ectopic pregnancy is an increasingly common and potentially catastrophic condition. Misdiagnosis of ectopic pregnancy is quite common. Delayed diagnosis may endanger the life of the patient but also decreases later the likelihood of a future successful pregnancy. ${ }^{19}$

There are a very few other disorders in obstetrics that has so many different presentations. The presentation of the patient may vary, some with minimal symptoms to a patient in a state of shock with massive haemoperitoneum. Some may present as a case of mass abdomen as in chronic ectopic. Vasomotor symptoms causing vertigo and syncope may be the presenting complaint.

Ectopic pregnancy may occur at any age from menarche to menopause. A study by Rose et al found maximum cases in age group of 21-25 years (43\%) which corroborated with the present study $(44 \%){ }^{20}$

In the present study, the maximum incidence of ectopic occurred between, parity 0 and 3 . In the study by Rose et al, as parity increases there is a decrease in the incidence of ectopic pregnancy. ${ }^{15}$ Munro Kerr and Eastman are of the opinion that there is no specific relation between parity and ectopic According to ICMR Multicentric Case Control Study (1990) of ectopic pregnancy, majority of women were young and had low parity. ${ }^{21,22}$
Ectopic pregnancies are generally diagnosed earlier due to their association with symptoms like bleeding and pain Amongst the complaints at the time of presentation the classical triad of abdominal pain, amenorrhaea and vaginal bleeding was present in $56 \%$ of the cases. In their studies Wakankar et al, and Jophy et al, have also reported classic triad in $53.84 \%$ and $66 \%$ cases respectively. ${ }^{23,24}$ This suggests that this classical triad is reliable most of the time for raising a suspicion of ectopic gestation. Amenorrhoea was present in $92 \%$ of the cases, which was also seen in studies of Jophy et al, (78.5\%) and Pal A et al (73\%). ${ }^{23,25}$ In the absence of amenorrhoea woman may be unaware of an ongoing pregnancy and hence may not anticipate a pregnancy associated complication. This subjects her to increased risk due to delayed diagnosis.

Vaginal bleeding was present in 56\% comparable to $65.4 \%$ and $66.6 \%$ in study by Rose et al, and Pendse et al, respectively. ${ }^{20,25}$ Other symptoms were giddiness, nausea, vomiting and syncopal attacks. Oumachigui et al reported fainting attacks in $18 \%$ and vomiting in $31 \% .{ }^{26}$

On general examination, pallor was seen in $86.1 \%$ of cases similar to other studies by Rose et al and Pendse et al, having incidence of $70.9 \%$ and $84.5 \%$ respectively. ${ }^{20,25}$ Abdominal tenderness was present in $72 \%$ cases in the present study and Rose et al also reported similar percentage $(83.9 \%) .^{20}$ The classical sign of cervical motion tenderness was present in $66 \%$ patients. Rose et al reported it to be $55.9 \% .^{20}$

The most common site for ectopic pregnancy is fallopian tube accounting for $90 \%$ of all ectopic pregnancy and rudimentary horn $2 \%$ in present study. It is comparable $89.11 \%$ and $1.98 \%$ respectively to Yakasai et al. ${ }^{15}$ Ectopic pregnancy, Bouyer et al, suggested sites of ectopic pregnancy as ovarian $(3.2 \%)$ in this study it was $2 \%$ results of our study is comparable.

The decision to perform conservative versus radical tubal surgery is on the basis of patients' history, desire for future fertility and surgical findings. Since most of our patients were referred with established signs of ruptured tubal pregnancy, and hemodynamic compromise, they needed emergency laparotomy and salpingectomy as life saving measures. High index of suspicion and awareness among clinicians, early use of routine transvaginal ultrasound to locate pregnancy and measuring hCG levels in any women in reproductive age who present with abdominal pain and vaginal bleeding, irrespective of amenorrhea is vital in diagnosing ectopic pregnancy at an early stage. This allows medical management and conservative tubal surgery with better reproductive potential.

Laparoscopy and laparotomy were performed on $54 \%$ and $36 \%$ cases respectively, which is comparable to hoover et al study. ${ }^{12}$ Success of treatment with medical management, laproscopy and laprotomy is $80 \%, 100 \%$ 
and $100 \%$ also comparable with study of hoover et al, which is $94.7 \%, 91.4 \%$ and $100 \%$ respectively. ${ }^{12}$

\section{CONCLUSION}

Ectopic pregnancy still remains potentially the most critical obstetrical emergency. Early diagnosis and management is now possible due to advanced diagnostic techniques like serum beta-hCG, high resolution ultrasonography and laparoscopy. Serum beta hCG values and high resolution transvaginal ultrasonography play an important role for diagnosis and management of ectopic pregnancy. Due to increased availability and reliability of serum beta hCG values with increased availability of expertise in TVS has made it possible to shift towards medical management in patients with unruptured ectopic pregnancy. TVS has sensitivity of 87$99 \%$ for the diagnosis of ectopic pregnancy.

Women should be encouraged regarding early reporting of missed periods and made aware of complications of ectopic pregnancy and necessity of seeking urgent medical help as early as possible so that early diagnosis and prompt conservative surgical or medical management of ectopic pregnancy can be done. This will not only help in reducing maternal mortality and morbidity rates but also go a long way in preservation of future fertility.

Early diagnosis, better health care facilities, good operative techniques and availability of blood and blood products help in reducing morbidity and mortality associated with ectopic pregnancy.

\section{ACKNOWLEDGMENTS}

Authors would like to thank Dr. Ajesh Desai, H.O.D. Obstetrics and Gynecology Department of GMERS Sola Civil Hospital, Ahmedabad, India.

\section{Funding: No funding sources}

Conflict of interest: None declared

Ethical approval: Not Required

\section{REFERENCES}

1. Berek JS. Berekand Novak's Gynaecology, 15th edition berek, Jonathan S. 15th ed. 2012; 622-651.

2. Brüggmann D, Kollascheck J, Quarcoo D, Bendels MH, Klingelhöfer D, Louwen F, et al. Ectopic pregnancy: exploration of its global research architecture using density-equalizing mapping and socioeconomic benchmarks. BMJ open. 2017 Oct 1;7(10):e01839.

3. Chatterjee S, Dey S, Chowdhury RG. Ectopic pregnancy in previously infertile women-subsequent per regnancy outcome after laparoscopic management. Al Ameen J Med Sci. 2009;2(1):67-72.

4. Parashi S, Moukhah S, Ashrafi M. Main risk factors for ectopic pregnancy: a case-control study in a sample of Iranian women. Int J Fertility Sterility. 2014;8(2):147.

5. Shaw JL, Dey SK, Critchley HO, Horne AW. Current knowledge of the aetiology of human tubal ectopic pregnancy. Human reproduction update. 2010 Jan 12; 16(4):432-44.

6. Li C, Zhao WH, Zhu Q, Cao SJ, Ping H, Xi X, et al. Risk factors for ectopic pregnancy: a multi-center case-control study. BMC pregnancy and childbirth. 2015 Aug 22; 15(1):187.

7. Yadav DP, Bhati I, Bhati BS. Ectopic pregnancy: a comprehensive analysis of risk factors and management. International Journal of Reproduction, Contraception, Obstet Gynecol. 2017 Jan 11;5(8):2723-7.

8. Weiss A, Beck-Fruchter R, Golan J, Lavee M, Geslevich Y, Shalev E. Ectopic pregnancy risk factors for ART patients undergoing the GnRH antagonist protocol: a retrospective study. Reproductive Bio Endocrinol. 2016 Mar 23;14(1):12.

9. Stovall TG, Ling FW. Single- dose methotrexate: an expanded clinical trial. Am J Obstet Gynecol. 1993; 168:1759-65.

10. Dighe M, Cuevas C, Moshiri M, Dubinsky T, Dogra VS. Sonography in first trimester bleeding. [Review]. J Clin Ultrasound. 2008;36(6):352-66.

11. Ong S, Wingfield M. Increasing incidence of ectopic pregnancy: is it iatrogenic?. Irish Med J. 1999 Aug;92(5):364-5.

12. Hoover KW, Tao G, Kent CK. Trends in the diagnosis and treatment of ectopic pregnancy in the United States. Obstet Gynecol. 2010 Mar $1 ; 115(3): 495-502$.

13. Bouyer J, Coste J, Fernandez H, Pouly JL, Job-Spira N. Sites of ectopic pregnancy: a 10 year populationbased study of 1800 cases. Human Reproduction. 2002 Dec 1; 17(12):3224-30.

14. Lozeau AM, Potter B. Diagnosis and management of ectopic pregnancy. Am Fam Physician. 2005 Nov 1;72(9):1707-14.

15. Yakasi IA, Abdullahi J, Abubakar IS, Management of ectopic pregnancy in Aminu Kano teaching hospital Kano Nigeria, A 3 -years. Glob Adv Res J Med Sci. 2012;1:181-5.

16. Daskalakis G, Pilalis A, Lykeridou K, Antsaklis A. Rupture of noncommunicating rudimentary uterine horn pregnancy. Obstet Gynecol. 2002 Nov 1;100(5, Part 2):1108-10.

17. Lee GS, Hur SY, Kown I, Shin JC, Kim SP, Kim SJ. Diagnosis of early intramural ectopic pregnancy. J Clin Ultrasound. 2005 May 1;33(4):190-2.

18. Osborn DA, Williams TR, Craig BM. Cesarean scar pregnancy. J Ultrasound Med. 2012 Sep 1;31(9):1449-56.

19. Jones EE. Ectopic pregnancy: Common and some uncommon misdiagnosis. Obstet Gynecol Clin North Am. 1991;18:55-72.

20. Jophy R, Thomas A, Mhaskar A. Ectopic pregnancy 5 years' experience. J Obstet Gynecol India. 2002;52(4):55-8. 
21. ICMR -task free project. Multicentric case control study of ectopic pregnancy in India. J Obstet Gynaecol India. 1990;40:425-30.24.

22. Wakankar R, Kedar K. Ectopic Pregnancy-A rising Trend. Int J Sci Stud. 2015 Aug;3(5):18-22.

23. Rose J, Thomas A, Mhaskar A. Ectopic pregnancy: Five years experience. J Obstet Gynecol India. 2002;52:55-8.

24. Shaikh S, Jampala S, Devi S, Malika M. A study of ectopic pregnancy in a tertiary care teaching hospital. Indian J Obstet Gynecol Res. 2016;3(2):132-6.

25. Pendse V. Ectopic pregnancy: a review of 110 cases. J Obstet Gynecol Ind. 1981;31:100-5.
26. Arora R, Rathore AM, Habeebullah S, Oumachigui A. Ectopic pregnancy-changing trends. J Indian Med Assoc. 1998 Feb; 96(2):53-4.

Cite this article as: Patel S, Das V, Desai A. Study of diagnosis and management of ectopic pregnancy. Int J Reprod Contracept Obstet Gynecol 2019;8:2465-70. 